\title{
СОВЕРШЕНСТВОВАНИЕ СОЦИАЛЬНОЙ ИНФРАСТРУКТУРЫ ОРГАНИЗАЦИИ КАК ОДНОГО ИЗ ФАКТОРОВ КОНКУРЕНТОСПОСОБНОСТИ КАДРОВОЙ ПОЛИТИКИ
}

\section{IMPROVING THE SOCIAL INFRASTRUCTURE OF THE ORGANIZATION AS ONE OF THE COMPETITIVENESS FACTORS OF PERSONNEL POLICY}

\section{Puryskina}

Summary: In this article, the systematization of the main directions for improving the social infrastructure of the personnel policy of enterprises belonging to the light industry complex is carried out, the factors that have the greatest impact on the effectiveness of the personnel policy are formulated and justified. The fundamental directions of the organization of social infrastructure as one of the factors of competitiveness of personnel policy are formulated. The paper evaluates and examines the results of the study of the mechanism of interaction between social and personnel policies based on the influence of factors of competitiveness, satisfaction and effective work of the personnel of light industry enterprises.

The measures aimed at building an effective personnel policy in the modern Russian conditions of economic development are proposed. Among them, it is necessary to distinguish the differentiated application of compensation packages in relation to employees of the enterprise.

Keywords: personnel policy, social infrastructure, personnel management, competitiveness factors.

\author{
Пурыскина Валентина Анатольевна \\ К.э.н., доцент, ФГБОУ ВО «Российский государственный \\ университет им. А.Н. Косыгина \\ (Технологии. Дизайн. Искусство)» \\ valya076@yandex.ru
}

Аннотация: В данной статье, проведена систематизация основных направлений по совершенствованию социальной инфраструктуры кадровой политики предприятий, относящихся к комплексу легкой промышленности, сформулированы и обоснованы факторы, оказывающие наибольшее влияние на эффективность кадровой политики. Сформулированы основополагающие направления организации социальной инфраструктуры как одного из факторов конкурентоспособности кадровой политики. В работе проведена оценка и рассмотрены результаты исследования механизма взаимодействия социальной и кадровой политики на основе влияния факторов конкурентности, удовлетворенности и эффективной работы персонала предприятий легкой промышленности.

Предложены мероприятия, направленные на построение эффективной кадровой политики в современных российских условиях развития экономики. Среди которых следует выделить дифференцированное применение компенсационных пакетов в отношении работников предприятия.

Ключевые слова: кадровая политика, социальная инфраструктура, управление персоналом, факторы конкурентоспособности.

\section{Введение}

$\Pi$ ри развернутой оценке системы управления персоналом на предприятиях легкой промышленности рекомендуется использовать комплексный подход, включающий изучение количественных, качественных и социальных показателей. Сфера социальных гарантий всегда является важной составляющей при оценке удовлетворенности работой и собственным рабочим местом. В случае оценки степени удовлетворенности собственным рабочим местом для опроса работников рекомендуется использовать форму анкеты. По результатам проведенного опроса можно определить наиболее значимый параметр социальной защищенности и степень удовлетворенности этим параметром. Результат этого исследования позволяет выявить проблемы, а также снизить уровень неудовлетворенности за счет привлечения сотрудников к дополнительным бонусам, предоставляемым организацией.
Для повышения конкурентоспособности предприятию необходимо работать в двух направлениях:

- обеспечить конкурентоспособность своей продукции, чтобы она могла конкурировать с продуктами других компаний;

- поднять эффективность работы предприятия и каждого из его подразделений, то есть проведение эффективной кадровой политики компании.

Также на конкурентоспособность напрямую влияет наличие устойчивого конкурентного преимущества особой компетенции, важной для деятельности организации, которая в меньшей степени представлена у конкурентов. Такое конкурентное преимущество имеет три характеристики:

- Основывается на важных для потребителей характеристиках продукта.

- Конкуренты не могут скопировать это преимущество в краткосрочной перспективе. 
- Преимущество устойчиво даже при изменениях среды. Источниками конкурентного преимущества может стать создание уникального торгового предложения, внедрение инноваций, создание бренда и т.д.

Существует несколько методов оценки конкурентоспособности. Все они имеют как свои плюсы, так и минусы. Матричные методы сравнивают компании с точки зрения маркетинговой оценки деятельности (матрицы Бостонской консалтинговой группы, Ансоффа, МакКинси и др.).

В зависимости от существующих трендов, экономической ситуации, доминирующих в обществе ценностей и других факторов потребители склоняются к приобретению товаров удовлетворяющего качества по низкой цене (появление «рационального» потребителя), то демонстрируют ажиотажный спрос на товары-новинки (вспомните спиннеры, которые внезапно «выстрелили» на рынке и про которые все благополучно забыли уже через полгода), то становятся более требовательными к дополнительным услугам: скорости доставки, качеству сопутствующего сервиса и т. д. Эти факторы вынуждают компании изменяться вслед за изменяющимися предпочтениями целевой аудитории.

На современном этапе развития российской экономики, вопрос эффективности кадровой политики стоит достаточно остро. В связи с этим кадровая политика эффективна только в том случае, если она опирается на элементы перспективного стратегического управления с учетом прогнозирования ситуации в будущем [1, с. 118].

Для развития социально ориентированной кадровой политики необходимо создание условий, для воспроизводства и развития кадрового потенциала, но и эффективно их использовать в своей кадровой политики $[2$, c. 90].

Основополагающими направлениями социальной инфраструктуры организации как одного из факторов конкурентоспособности кадровой политики могут выступать:

- комплекс мер, направленных на сохранение квалифицированных кадров, и их профессиональной мобильности;

- трудоустройство рабочих;

- стимулирование рабочих к повышению квалификации, организация и формирование внутриорганизационного обучения персонала;

- участие в социальном обеспечении и страховании;

- обеспечение социальной защиты персонала.
В социальной инфраструктуре организации как одного из факторов конкурентоспособности кадровой политики значительная роль отводится социальному обеспечению.

Например, сотрудники предприятий легкой промышленности летом могут провести каникулы в спортивных лагерях, базах отдыха, которые находятся в собственности данных организаций. Также в течение года сотрудникам предприятий сферы легкой промышленности предоставляется скидка 30\% на санаторно-курортное лечение, а также и их детям предоставляется возможность провести каникулы в летних лагерях со скидкой от 30 до $50 \%$.

\section{Методы исследования.}

Сегодня на российских предприятиях особенно актуальной и острой является социальная поддержка работников в сфере легкой промышленности. Учитывая массу социальных факторов, характеризующих качество трудовой жизни персонала данной отрасли можно выделить такие как, оплата труда, уровень доступности жилья, условия труда, межличностные отношения и микроклимат в рабочем коллективе, политика компании и администрации (рисунок 1).

По нашему мнению в теории Ф. Гертсберга, необходимо внести некоторые поправки в перечень интегративных социальных факторов. В частности, фактор «степень непосредственного надзора за работой» имеет смысл заменить на коэффициент «степень обеспеченности жилья» [4].

Ключевыми факторами выступают показатели заработной платы и степени обеспеченности жилья. Учитывать необходимо также отношения с начальниками, коллегами, подчиненными, вызывающие положительный или в разной степени негативный психологический климат в группах и между ними.

Использование данной модели позволяет абсолютно однозначно выявить конечную эффективность проведения социальной политики по тому влиянию, которое оказывают на работников планируемые действия в отношении социального развития трудового коллектива. Так что регулирование и обеспечение качества трудовой жизни работника зависит от уровня проводимой в данной компании социальной политики.

На конкурентоспособность кадровой политики оказывают большое влияние такие факторы, как удовлетворенность работой и качество трудовой жизни персонала на предприятиях. 


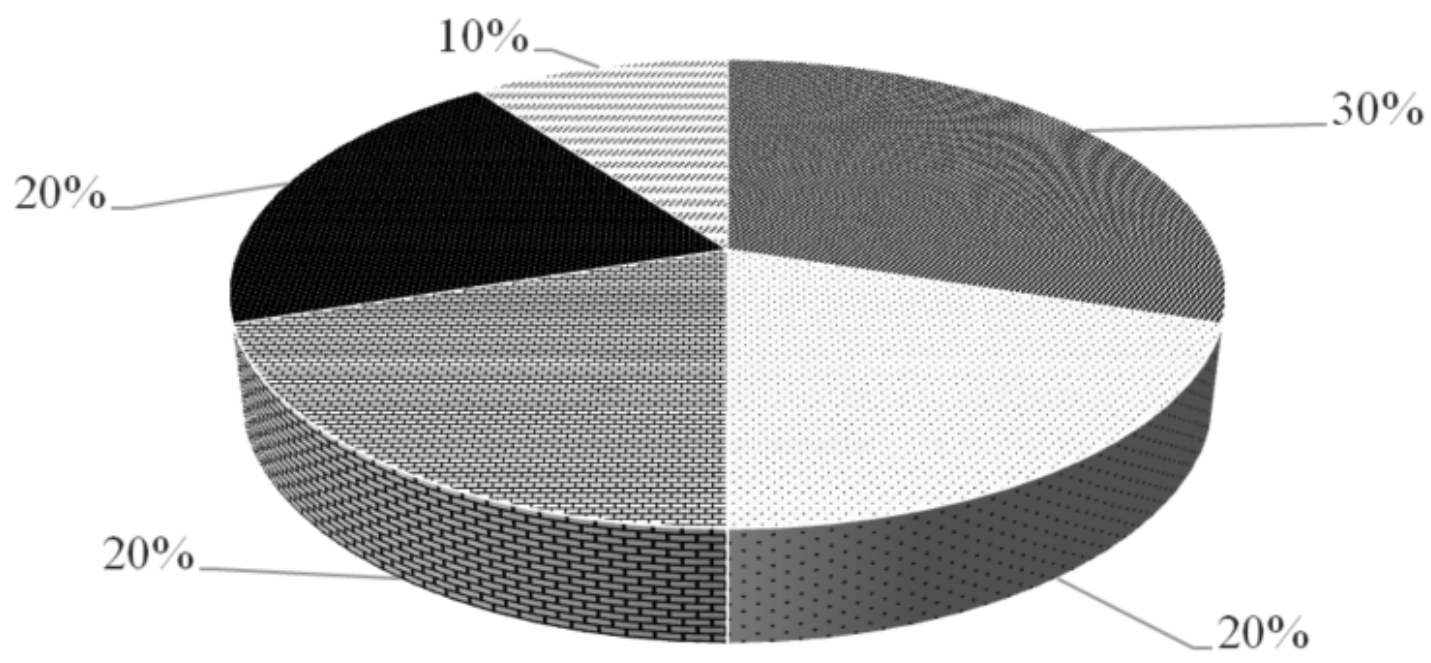

\% Зарплата

Доступность жилья

ғ Рабочий настрой

- Межличностные отношения и микроклимат в рабочем коллективе " Политика компании и администрации

Рис. 1. Структура факторов [3, с. 82]

Полученные результаты.

Социальная инфраструктура организации как одного из факторов конкурентоспособности кадровой политики будет эффективной, если оказываемые социальные услуги отражают особенность деятельности организации. Механизм взаимодействия социальной и кадровой политики на основе влияния факторов конкурентоспособности кадровой политики на удовлетворенность работой представлен на рисунке 2.

Сильная социальная инфраструктура организации как одного из факторов конкурентоспособности кадровой политики выступает важнейшей составляющей стабилизации социально-трудовых отношений в компаниях, повышения мотивации, прироста производительности и качества работы персонала, сохранения и привлечения высококвалифицированных специалистов. Принципы управления создаются на основе социальной и кадровой политики. На рисунке 2 видно, что удовлетворение социальных потребностей работников и создание благоприятных условий труда способствуют возникновению у работников стремления внести свой вклад в эту систему. Это, в свою очередь, приводит к сохранению существующего персонала и привлечению новых работников, максимальному использованию работниками своих способностей и возможностей, обеспечивающих прирост производительности, повышение эффективности и качества работы рабочих, к повышению квалификации специалистов.

Сфера социальных гарантий всегда является важной составляющей при оценке удовлетворенности работой и собственным рабочим местом. В случае оценки степени удовлетворенности собственным рабочим местом для опроса работников рекомендуется использовать форму анкеты, которая приведена в таблице 1.

По результатам такого опроса можно определить наиболее значимый параметр социальной защищенности и степень удовлетворенности этим параметром. Результат этого исследования позволяет выявить проблемы, а также снизить уровень неудовлетворенности за счет привлечения сотрудников к дополнительным бонусам, предоставляемым организацией. Увеличение дохода сотрудников предприятия в качестве рекомендации предполагает создание пакета льгот или компенсаций для оказания помощи работникам в решении социальных бытовых проблем, для социальной защиты работников.

Варианты компенсационного пакета разрабатываются с одинаковой стоимостью, но с разным наполнением для обеспечения выбора сотрудником [5, с. 69]. 


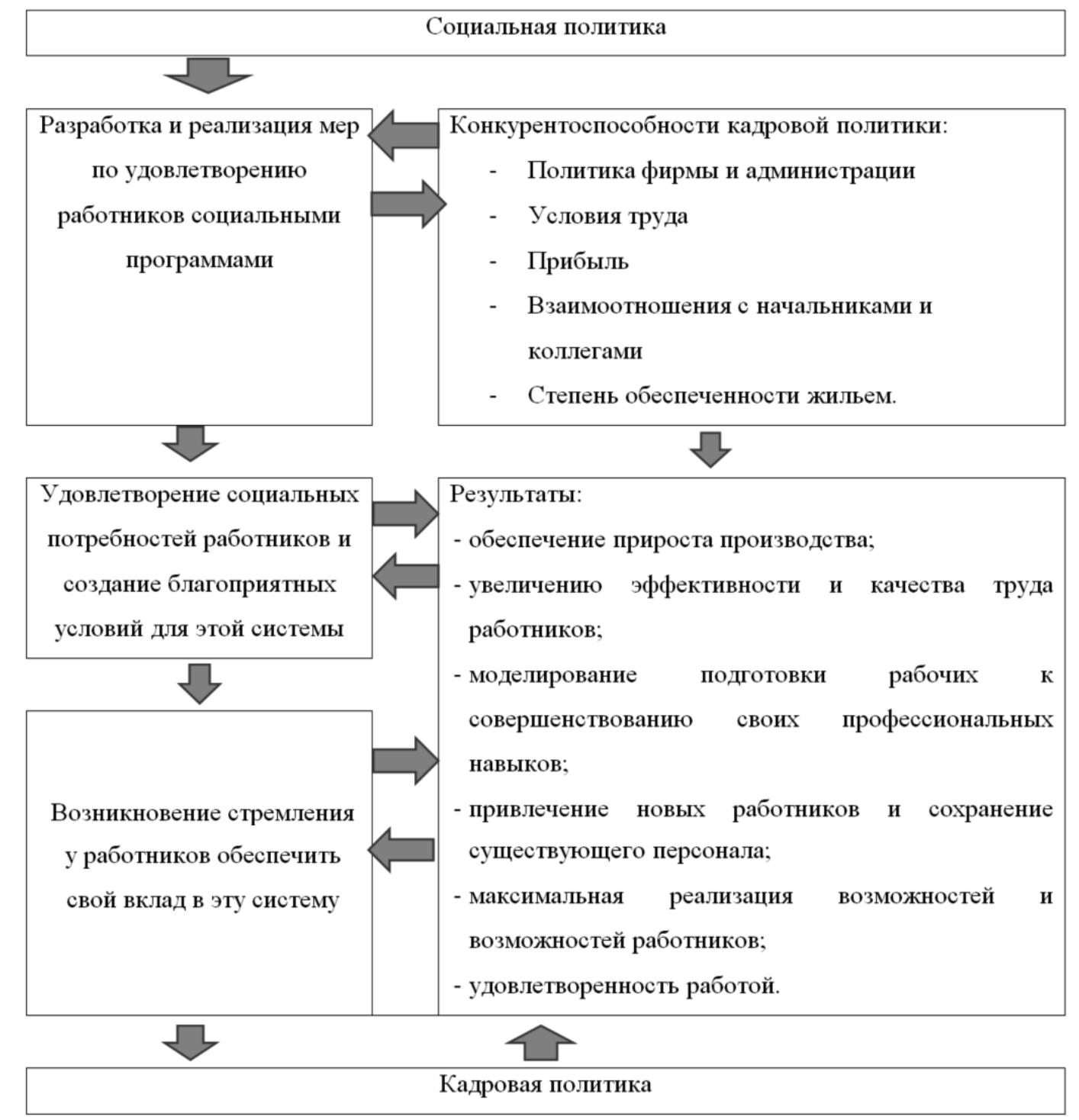

Рис. 2. Механизм взаимодействия социальной и кадровой политики

на основе влияния факторов конкурентности и удовлетворенности работой $[6$, с. 230, 7]

Таблица 1.

Форма анкеты.

\begin{tabular}{|l|l|l|l|l|l|}
\hline \multicolumn{1}{|c|}{ Имя } & Важен для вас & \multicolumn{3}{c|}{ В \% } \\
\cline { 5 - 6 } 1. Социальные выплаты и льготы & & & & & \\
\hline 2. Предоставление жилья & & & & \\
\hline 3. Услуги общественного питания. & & & & \\
\hline 4.Предоставление санаторно-курортных путевок. & & & & \\
\hline 5. Спортивные сооружения & & & & \\
\hline 6.0беспечение медицинского осмотра & & & & \\
\hline 7. Организация праздничных и торжественных & & & & \\
\hline мероприятий & & & & \\
\hline 8.Предоставление детских новогодних подарков. & & & & & \\
\hline
\end{tabular}


Таблица 2.

Варианты компенсационного пакета для работодателя в зависимости от качественных характеристик работника.

\begin{tabular}{|c|c|c|c|c|c|c|c|c|c|c|c|c|}
\hline \multirow{3}{*}{$\begin{array}{c}\text { Варианты компенсационного пакета } \\
\text { Обеспечение медицинского обследования и осмотра }\end{array}$} & \multicolumn{4}{|c|}{ Лидеры } & \multicolumn{4}{|c|}{ Специалисты } & \multicolumn{4}{|c|}{ Другие работники } \\
\hline & \multicolumn{2}{|c|}{$>5$ лет } & \multicolumn{2}{|c|}{$>5$ лет } & \multicolumn{2}{|c|}{ > 5 лет } & \multicolumn{2}{|c|}{$>5$ лет } & \multicolumn{2}{|c|}{$>5$ лет } & \multicolumn{2}{|c|}{ > 5 лет } \\
\hline & + & & + & & + & & + & & + & & + & \\
\hline Оплата путевок в дома отдыха & + & & + & & & + & + & & + & & + & + \\
\hline Предоставление льготных кредитов & & + & + & & & + & + & & & + & + & \\
\hline $\begin{array}{l}\text { Единовременные выплаты на важные жизненные события (юбилеи, } \\
\text { похороны) }\end{array}$ & + & & & + & + & & & + & & + & & + \\
\hline Единовременная материальная поддержка семье работника & + & & & + & + & & & + & & + & & + \\
\hline Оплата дополнительного обучения сотрудников & + & & & + & + & & + & & + & & & + \\
\hline $\begin{array}{l}\text { Компенсация дорогостоящего лечения тяжелого заболевания } \\
\text { близких родственников }\end{array}$ & & + & + & & & + & + & & + & & + & \\
\hline Бесплатные билеты & & & & & & & & & & + & & + \\
\hline Предоставление ведомственного жилья или его оплата & & & & & & & & & & & & \\
\hline Предоставление служебного автомобиля & & + & & + & & & & & & & & \\
\hline 0беспечение более комфортных условий труда & & & & + & & & & + & & & & \\
\hline Ценные подарки к юбилеям & & & & + & & & & + & & & & + \\
\hline
\end{tabular}

\section{Выводы.}

Исходя из проведенного исследования можно сделать вывод, что совершенствование социальной инфраструктуры организации как одного из факторов конкурентоспособности кадровой политики будет способствовать привлечению и удержанию компетентных и необходимых сотрудников организации, стимулированию и патриотическому отношению к организации, а также эффективной и продуктивной работе.

Предоставляемые социальные услуги и гарантии выступают материальной поддержкой для новых сотрудников, что позволяет создавать благоприятный климат на предприятиях легкой промышленности, и стимулирует профессиональное развития работников.

К положительным результатам от реализации данного комплекса мер по повышению системной эффективности управления персоналом следует отнести:

- обеспечение адекватного уровня жизни персонала;
- воплощение индивидуальных способностей сотрудников;

- позитивный социально-психологический климат;

- снижение уровня текучести кадров.

Таким образом, основной целью социальной инфраструктуры организации как одного из факторов конкурентоспособности кадровой политики выступает эффективная система управления персоналом, основанная на социальных гарантиях и государственной поддержки.

Ожидаемым эффектом от внедрения предлагаемых мероприятий по оптимизации социальной инфраструктуры предприятия как одного из факторов конкурентоспособности кадровой политики является внедрение, мер по стимулированию персонала, которые позволят повысить качество HR-функций, направленных на повышение результативности труда работников персонала, а также формирование оптимальной для конкретного предприятия системы мер по совершенствованию социально-трудовой составляющей кадровой политики.

\section{ЛИТЕРАТУРА}

1. Дырин С. Управление персоналом: от кадрового подхода - к многоаспектному // Кадровик. - 2010. - № 9. - С. 117-120.

2. Зеленцов А.Б. Формирование и реализация кадровой политики в системе социально-трудовых отношений промышленных организаций: дис. кан. эк-х. наук. - М.: 2015. -175 c.

3. Андреева Н.В., Набатчикова С.Б., Огородникова Е.П. Подготовка и переподготовка персонала в области АПК // Никоновские чтения. 2020. № 25. С. 79-83.

4. Ильенков Д.А. Управление по целям: преимущества и недостатки // Экономика и менеджмент инновационных технологий. 2015. № 2 [Электронный pecypc]. URL: http://ekonomika.snauka.ru/2015/02/7151 (дата обращения: 04.2021) 
5. Чубукова, С.Г. Стратегии развития информационного общества и направления развития законодательства [Текст] / С.Г. Чубукова // Правовая информатика. - 2017. - № 2. - С. 67-72

6. Боровских Н.В., Кипервар Е.А. Кадровая политика предприятия: перспективы формирования в условиях цифровизации экономики // Вестник Белгородского университета кооперации, экономики и права №4 (77) 2019. С. 223-233

7. Российский экспортный центр [Электронный ресурс]: Офиц. веб-сайт. - Режим доступа: https://www.exportcenter.ru

$$
\text { () Пурыскина Валентина Анатольевна (valya076@yandex.ru). }
$$

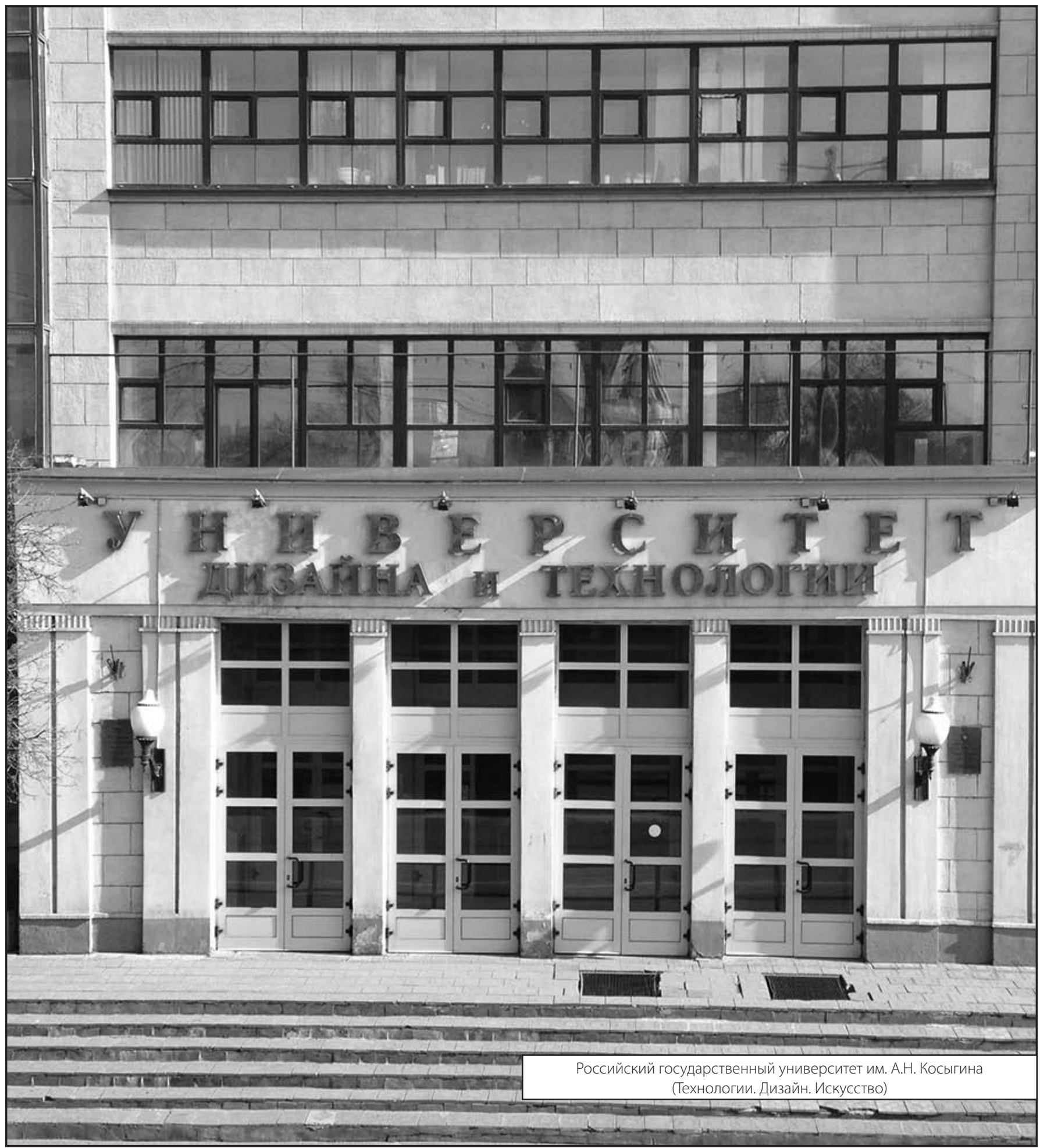

